\title{
Expression and prognostic significance of microR- NAs in Korean patients with myelodysplastic syndrome
}

\author{
Yunsuk Choi ${ }^{1,}$, Eun-Hye Hur ${ }^{2,}$, Ju Hyun Moon ${ }^{2}$, Bon-Kwan Goo ${ }^{2}$, Dae Ro Choi ${ }^{3}$, and Je-Hwan Lee ${ }^{2}$
}

\begin{abstract}
${ }^{1}$ Department of Hematology and Oncology, Ulsan University Hospital, University of Ulsan College of Medicine, Ulsan; ${ }^{2}$ Department of Hematology, Asan Medical Center, University of Ulsan College of Medicine, Seoul; ${ }^{3}$ Department of Internal Medicine, Hallym University Chuncheon Sacred Heart Hospital, Chuncheon, Korea
\end{abstract}

Received: July 20, 2016

Revised : November 5, 2016

Accepted: June 17, 2017

\section{Correspondence to}

Je-Hwan Lee, M.D.

Department of Hematology,

Asan Medical Center, University of Ulsan College of Medicine,

88 Olympic-ro 43-gil, Songpa-gu,

Seoul 05505, Korea

Tel: +82-2-3010-3218

Fax: +82-2-3010-6885

E-mail:jhlee3@amc.seoul.kr

*These authors contributed equally to this work.
Background/Aims: Various alterations of microRNA (miRNA) expression have been reported in myelodysplastic syndrome (MDS). We aimed to investigate the unique patterns and prognostic significance of miRNA expression in Korean patients with MDS.

Methods: Bone marrow mononuclear cells were collected from eight healthy controls and 26 patients with MDS, and miRNAs were isolated and assessed via quantitative real-time polymerase chain reaction for selected miRNAs, including miR-21, miR-124a, miR-126, miR-146b-5p, miR-155, miR-182, miR-200c, miR-3425p, miR-708, and Let-7a.

Results: MiR-124a, miR-155, miR-182, miR-20oc, miR-342-5p, and Let-7a were significantly underexpressed in patients with MDS, compared to healthy controls. MiR-21, miR-126, 146b-5p, and miR-155 transcript levels were significantly lower in international prognostic scoring system lower (low and intermediate-1) risk MDS than in higher (intermediate-2 and high) risk MDS. Higher expression levels of miR-126 and miR-155 correlated with significantly shorter overall survival and leukemia-free survival. Higher miR-124a expression also tended to be related to shorter survivals.

Conclusions: Although our study was limited by the relatively small number of patients included, we identified several miRNAs associated with pathogenesis, leukemic transformation, and prognosis in MDS.

Keywords: Myelodysplastic syndromes; MIRN126 microRNA, human; hsa-146b5p; MIRN155 microRNA, human; MIRN200 microRNA, human

\section{INTRODUCTION}

Myelodysplastic syndrome (MDS) is a genetically heterogeneous clonal disorder that is characterized by dysplasia and ineffective hematopoiesis [1]. The disease is more prevalent in older age [2], and it is usually stratified according to clinical variables that predict survival times and risk of transformation to acute myeloid leukemia (AML) $[3,4]$. Although the pathogenesis of MDS has not been fully understood, various alterations of microRNAs (miRNAs) have been reported in MDS [5]. MiRNAs are short non-coding RNAs that are 18 to 25 nucleotides in length and are encoded as precursor hairpin intermediate RNAs [6]. Mature miRNAs are produced by endonuclease-mediated steps and incorporated into the RNA, where miRNAs can cleave messenger RNA and repress protein translation [6]. MiRNAs also reportedly control transcription by directly regulating DNA meth- 
ylation [7]. Some miRNAs are associated with myeloid development and function [8], and some miRNAs have tumor-suppressor and oncogenic activities. Recently, several miRNAs, including miR-17-5p, miR-20a, miR-21, and miR-194-5p, were proposed as prognostic markers in MDS [9-11]. We aimed to investigate the disease-specific expression patterns of selected miRNAs in MDS and to evaluate the clinical implications of miRNA expression as it relates to predicting outcomes of patients with MDS.

\section{METHODS}

\section{Patients}

A total of 26 patients with MDS and eight healthy controls were included in this study. A diagnosis of MDS was made according to standard criteria [12]. This study was approved by the Institutional Review Board of Asan Medical Center, Seoul, Korea (2012-0217), and written informed consent was obtained from each patient. Clinical and laboratory data for patients with MDS were retrospectively obtained. Risk was assessed at the time of MDS diagnosis according to the international prognostic scoring system (IPSS) and the revised IPSS (R-IPSS) $[3,4]$.

\section{Quantitative polymerase chain reaction for miRNA}

All bone marrow samples were collected before the patient received any treatment other than transfusion, androgens, or growth factors. Total miRNAs were isolated from bone marrow mononuclear cells using the miRNeasy Mini Kit (Qiagen, Hilden, Germany), according to the manufacturer's instructions. We performed real-time quantitative polymerase chain reaction (PCR) using a miScript SYBR green PCR kit (Qiagen) for 10 miRNAs: miR-21, miR-124a, miR-126, miR-146b-5p, miR-155, miR-182, miR-20oc, miR-342-5p, miR-708, and Let-7a. The reaction proceeded at $95^{\circ} \mathrm{C}$ for 15 minutes, followed by 40 cycles of $96^{\circ} \mathrm{C}$ for 15 seconds, $55^{\circ} \mathrm{C}$ for 30 seconds, $70^{\circ} \mathrm{C}$ for 30 seconds, on a LightCycler 96 (Roche, Indianapolis, IN, USA). The cycle threshold (Ct) values for all samples were normalized to $\mathrm{Ct}$ values of RNU6. Relative expression levels were calculated using the comparative $\mathrm{Ct}\left(2^{-\triangle \Delta \mathrm{Ct}}\right)$ method. All reactions were performed in triplicate.

\section{Statistical analysis}

Relative expressions of miRNAs between samples were compared using the nonparametric Mann-Whitney $U$ test or Kruskal-Wallis test. Spearman rank correlation coefficient $\left(r_{s}\right)$ was calculated for statistical dependence of expression levels between miRNAs. Overall survival (OS) was calculated from the time of MDS diagnosis to the date of death or last follow-up. Leukemia-free survival (LFS) was calculated from the time of MDS diagnosis to the date of leukemic transformation or death from any cause. Survival probabilities were estimated by the Kaplan-Meier method, and differences in survival distributions were compared using the log-rank test. Statistical analyses were performed using SPSS version 21.0 software (IBM Corp., Armonk, NY, USA). For all analyses, the $p$ values were two-tailed, and $p<0.05(p<0.01$ for Spearman rank correlation analysis) was considered statistically significant.

\section{RESULTS}

\section{Patient characteristics}

There were 15 males and 11 females included in this study. The median patient age was 57 years (range, 28 to 81) (Table 1). Bone marrow blast percentages were $<5 \%$ in 13 patients and $\geq 5 \%$ in 13 patients. Fifteen patients had lower risk (low or intermediate-1), and 11 had higher risk (intermediate-2 or high) MDS, according IPSS risk groups.

\section{MicroRNA expression in patients with MDS}

Relative expression of each miRNA was analyzed using RNU6 as an endogenous control in patients with MDS and normal controls (Fig. 1). Compared to normal controls, patients with MDS showed significantly lower levels of miR-124a (median, 1.471 vs. 0.09o; $p=0.010$ ), miR155 (median, 0.910 vs. $0.165 ; p<0.001$ ), miR-182 (median, 0.924 vs. $0.290 ; p=0.012$ ), miR-342-5p (median, 1.546 vs. $0.311 ; p<0.001$ ), and Let-7a (median, 1.032 vs. $0.319 ; p=$ 0.004).

When patients were divided into two groups according to IPSS risk stratification (lower [low and intermediate-1] vs. higher [intermediate-2 and high]), there were significant differences in miR-21 (median, 0.773 vs. 1.212; $p=0.036$ ), miR-126 (median, 0.822 vs. 1.125; $p=0.032$ ), 
Table 1. Patient characteristics at the time of diagnosis

\begin{tabular}{|c|c|}
\hline Characteristic & Value \\
\hline Sex, male/female & $15(57.7) / 11(42.3)$ \\
\hline Age, yr & $58.0(28-81)$ \\
\hline Hemoglobin, g/dL $(\mathrm{n}=26)$ & $8.0(4.2-10.4)$ \\
\hline WBC count, $\times 10^{3} / \mu \mathrm{L}(\mathrm{n}=26)$ & $3.7(0.8-35.9)$ \\
\hline $\mathrm{ANC}, / \mu \mathrm{L}(\mathrm{n}=26)$ & $1,332(96-31,959 \cdot 9)$ \\
\hline Circulating blast count, $\%(n=26)$ & $0(0-12)$ \\
\hline Platelet count, $\times 10^{3} / \mu \mathrm{L}(\mathrm{n}=26)$ & $66.0(7-697)$ \\
\hline $\mathrm{LDH}$ (conversion), mg/dL $(\mathrm{n}=26)$ & $272(109-846)$ \\
\hline Bone marrow cellularity, $\%(n=25)$ & $70.0(25-100)$ \\
\hline Bone marrow blasts, $\%(n=26)$ & $4.6(0-18.2)$ \\
\hline \multicolumn{2}{|l|}{ MDS subtype $(n=26)$} \\
\hline RCUD & $3(11.5)$ \\
\hline RARS & $1(3.8)$ \\
\hline RCMD & $7(26.9)$ \\
\hline RAEB-1 & $4(15 \cdot 4)$ \\
\hline RAEB-2 & $9(34.6)$ \\
\hline MDS-U & $2(7 \cdot 7)$ \\
\hline De novo/secondary MDS & $25(96.2) / 1(3.8)$ \\
\hline \multicolumn{2}{|l|}{ Cytogenetic risk group $(n=26)^{a}$} \\
\hline Good & $15(57 \cdot 7)$ \\
\hline Normal & 13 \\
\hline$-Y$ alone & 1 \\
\hline $\operatorname{del}(20 \mathrm{q})$ alone & 1 \\
\hline Intermediate & $6(23.1)$ \\
\hline$+\operatorname{add}(1 \mathrm{p})$ & 1 \\
\hline$+8, \operatorname{add}(17 q)$ & 1 \\
\hline $\mathrm{t}(3 ; 5)$ & 1 \\
\hline $\operatorname{del}(13 q)$ & 1 \\
\hline Others & 2 \\
\hline Poor (complex [ $\geq 3$ abnormalities]) & $5(19.2)$ \\
\hline \multicolumn{2}{|l|}{ IPSS risk category $(n=26)$} \\
\hline Low & $2(7.7)$ \\
\hline Intermediate-1 & $13(50.0)$ \\
\hline Intermediate-2 & $6(23.1)$ \\
\hline High & $5(19.2)$ \\
\hline \multicolumn{2}{|l|}{ R-IPSS risk category $(n=26)$} \\
\hline Very low & $\mathrm{O}$ \\
\hline Low & $5(19.2)$ \\
\hline Intermediate & $9(34.6)$ \\
\hline High & $4(15 \cdot 4)$ \\
\hline Very high & $8(30.8)$ \\
\hline ECOG performance status, o/1/2 & $1(3.8) / 22(84.6) / 3(11.5$ \\
\hline
\end{tabular}

Values are presented as number (\%) or median (range). WBC, white blood cells; ANC, absolute neutrophil count; LDH, ---; MDS, myelodysplastic syndrome; RCUD, refractory cytopenia with unilineage dysplasia; RARS, refractory anemia with ringed sideroblasts; RCMD, refractory cytopenia with multilineage dysplasia; RAEB, refractory anemia with excess of blasts; MDS-U, myelodysplastic syndrome-unclassifiable; IPSS, international prognostic scoring system; R-IPSS, revised IPSS; ECOG, Eastern Cooperative Oncology Group.

${ }^{a}$ According to IPSS cytogenetic risk groups.
miR-146b (median, 0.560 vs. 1.319; $p=0.006$ ), and miR-155 expression levels (median, 0.098 vs. $0.220 ; p=0.002$, respectively) between lower and higher risk groups (Fig. 2).

MiR-155 expression positively correlated with miR342-5p $\left(r_{s}=0.710, p<0.001\right)$ and Let-7a $\left(r_{s}=0.650, p<\right.$ $0.001)$ expression levels, and there was also a significant positive relationship between miR-200 and miR-342-5P $\left(r_{s}=0.855, p<0.001\right)$ (Table 2). Table 3 lists common target genes for the positively correlated miRNAs [13].

\section{Prognostic significance of miRNA expression in MDS patients}

With a median follow up duration of 14.8 months (range, 0.4 to 83.8 ) for surviving patients, 2-year survival probabilities were $44.0 \%$ for OS and $44.6 \%$ for LFS. Prognostic factor analysis showed that old age ( $\geq 65$ years) and high bone marrow blast percentage ( $\geq 5 \%$ ) were significantly associated with shorter OS and LFS (Table 4). IPSS and R-IPSS were also used to stratify patients into different OS and LFS groups. The 2-year OS probability was significantly more inferior for patients with higher expression levels of miR-126 (24.2\% vs. $68.2 \%, p=0.039)$ and miR-155 (o\% vs. $60.8 \%, p=0.003$ ) than for those with lower expression levels of each miRNA (Fig. 3). The 2-year LFS probability was also significantly more inferior for patients with higher expression levels of miR-126 (25.0\% vs. $68.2 \%, p=0.038$ ) and $\operatorname{miR}-155$ (o\% vs. $61.1 \%, p=0.002$ ) than those with lower expression levels (Fig. 3). Higher expression levels of miR-124a also tended to be associated with lower OS (16.7\% vs. $54.1 \%$ at 2 years, $p=0.084$ ) and lower LFS (16.7\% vs. $54.6 \%$ at 2 years, $p=0.054$ ), although the differences were not statistically significant.

\section{DISCUSSION}

In the present study, we found that MDS patients had significantly lower expression levels of several miRNAs, including miR-124a, miR-155, miR-182, miR-200c, miR-342-5p, and Let-7a, than normal healthy volunteers. Although dysregulation of miR-20oc has never been reported in MDS, it has been noted in solid tumors, including colorectal cancer, renal cell carcinoma, and ovarian cancer [14-16]. MiR-20oc regulates proliferation, migration, and invasion in breast and ovarian cancers [17], and the expression of miR-20oc in endometrial, 


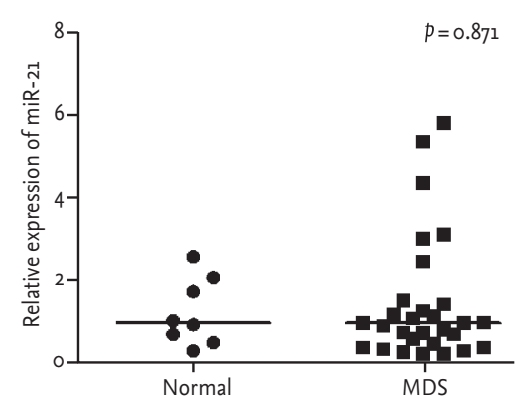

A

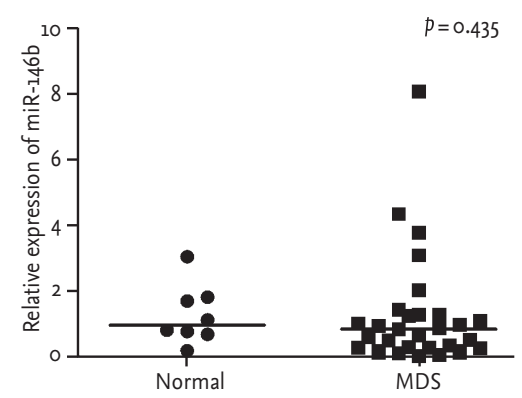

D

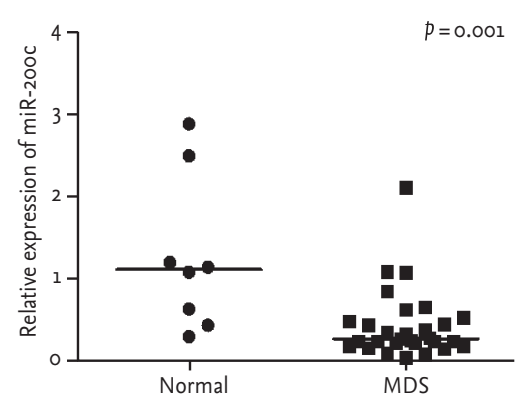

G

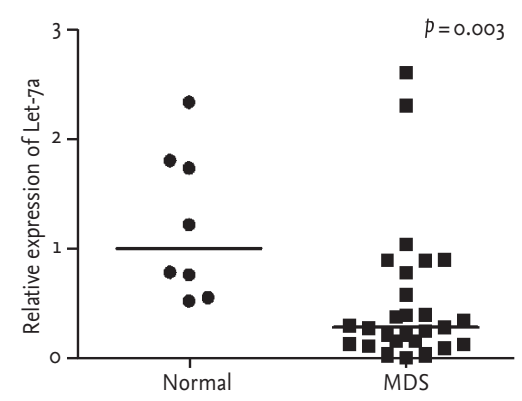

J

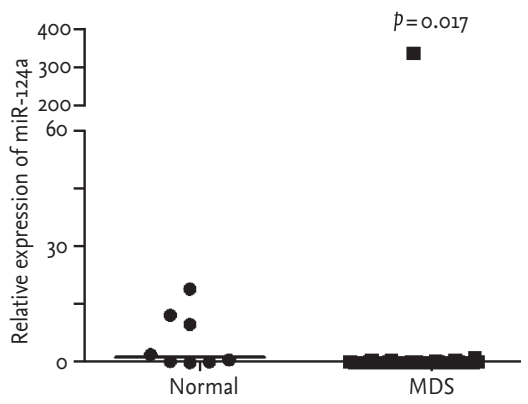

B

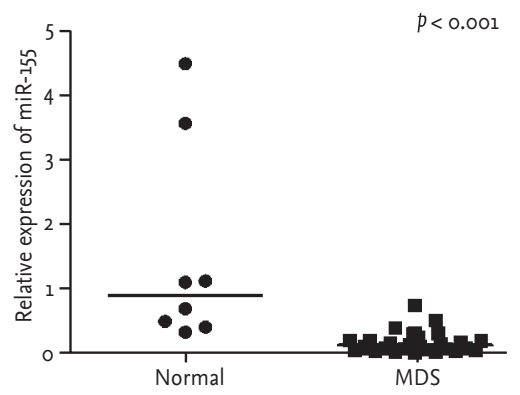

E

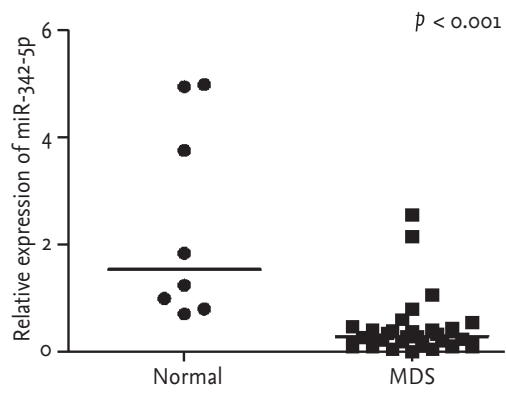

$\mathbf{H}$

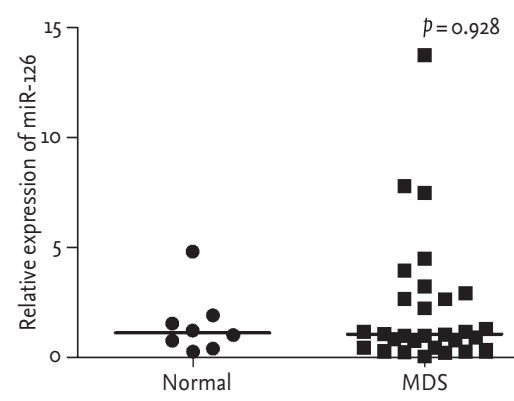

C

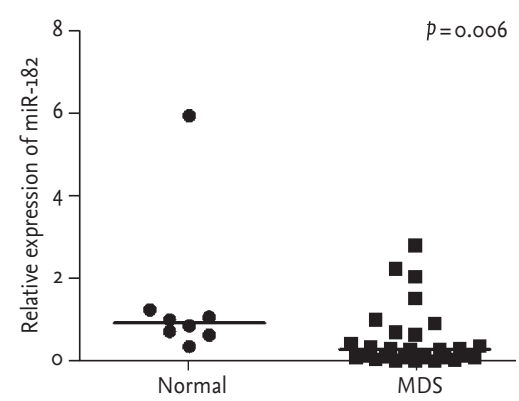

$\mathbf{F}$

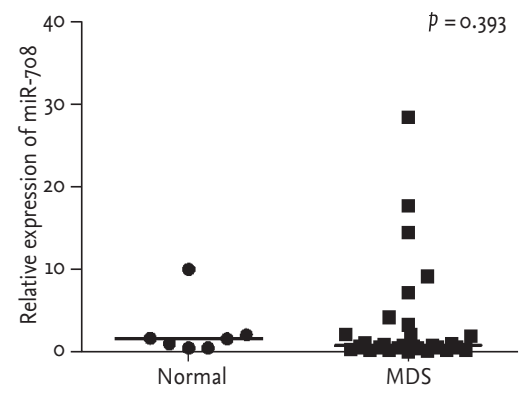

I

Figure 1. Relative expression of microRNAs using RNU6 as an endogenous control in 26 patients with myelodysplastic syndrome and eight normal controls. Bars indicate median values. (A) miR-21 (B) miR-124a, (C) miR-126, (D) miR-146b, (E) miR-155, (F) miR-182, (G) miR-20oc, (H) miR-342-5p, (I) miR708, (J) Let-7a. MDS, myelodysplastic syndrome. 

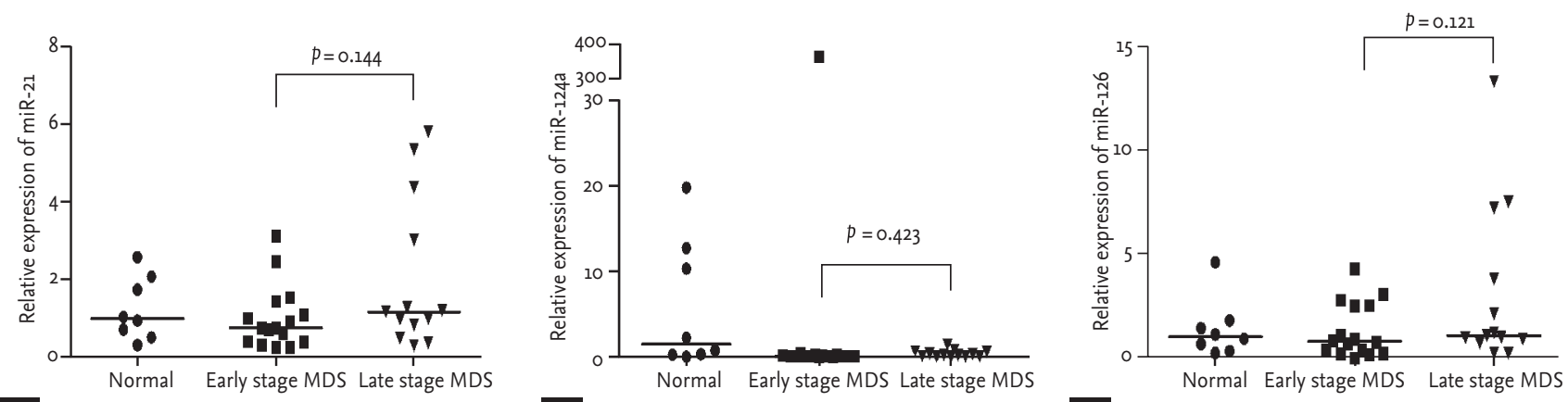

A

\section{B}

\section{C}
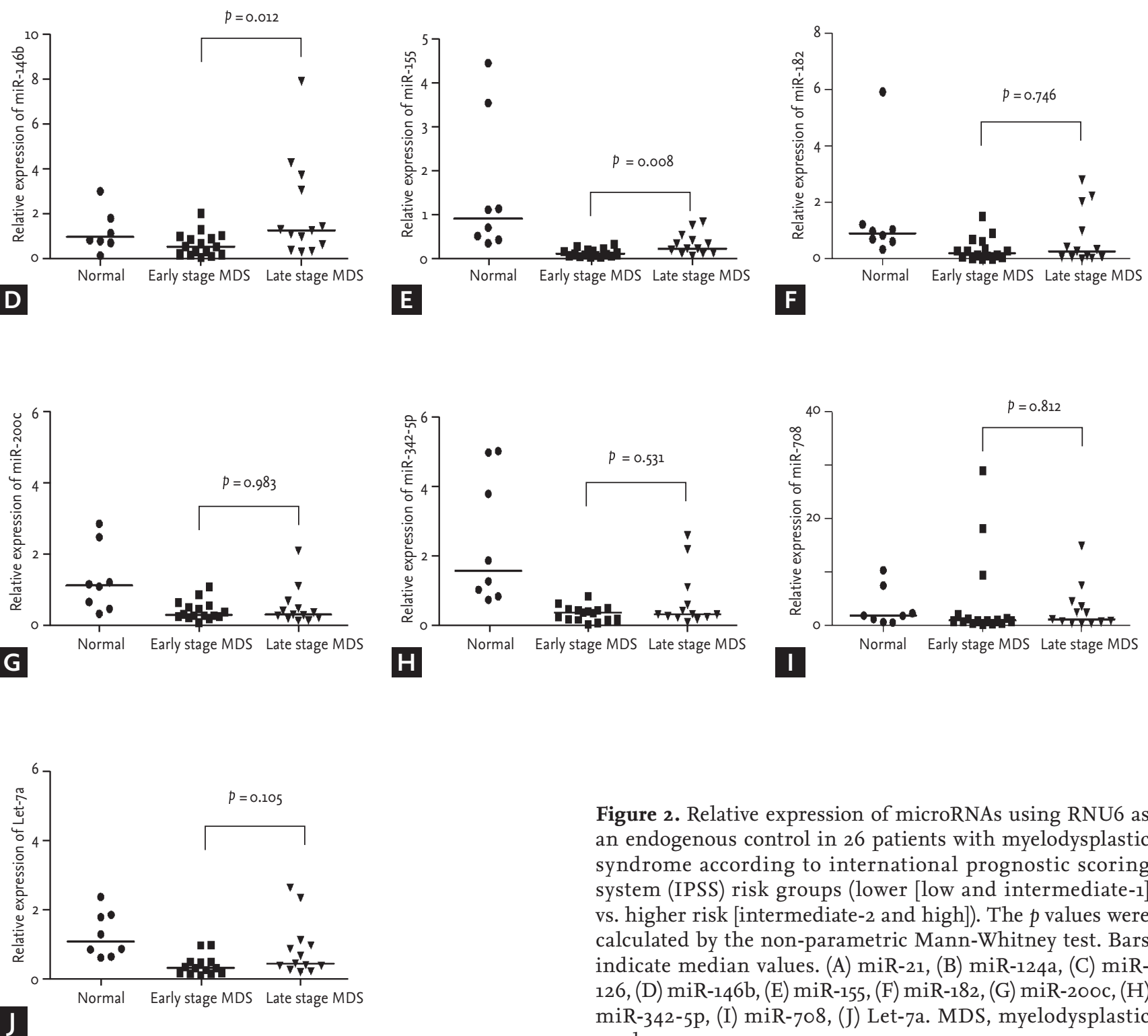

Figure 2. Relative expression of microRNAs using RNU6 as an endogenous control in 26 patients with myelodysplastic syndrome according to international prognostic scoring system (IPSS) risk groups (lower [low and intermediate-1] vs. higher risk [intermediate-2 and high]). The $p$ values were calculated by the non-parametric Mann-Whitney test. Bars indicate median values. (A) miR-21, (B) miR-124a, (C) miR126, (D) miR-146b, (E) miR-155, (F) miR-182, (G) miR-200c, (H) miR-342-5p, (I) miR-708, (J) Let-7a. MDS, myelodysplastic syndrome. 
Table 2. Correlation of expression levels between microRNAs

\begin{tabular}{|c|c|c|c|c|c|c|}
\hline & $\operatorname{miR}-124$ & $\operatorname{miR}-155$ & $\operatorname{miR}-182$ & miR-200c & miR-342-5p & Let-7a \\
\hline \multicolumn{7}{|l|}{$\operatorname{miR}-124$} \\
\hline$r_{\mathrm{s}}$ & - & 0.512 & 0.478 & 0.005 & 0.028 & $0.682^{a}$ \\
\hline$p$ value & & 0.007 & 0.014 & 0.980 & 0.893 & $<0.001$ \\
\hline \multicolumn{7}{|l|}{ miR-155 } \\
\hline$r_{\mathrm{s}}$ & 0.512 & - & 0.348 & 0.514 & $0.710^{\mathrm{a}}$ & $0.650^{a}$ \\
\hline$p$ value & 0.007 & & 0.081 & 0.007 & $<0.001$ & 0.001 \\
\hline \multicolumn{7}{|l|}{$\operatorname{miR}-182$} \\
\hline$r_{\mathrm{s}}$ & 0.478 & 0.348 & - & -0.040 & -0.003 & $0.717^{\mathrm{a}}$ \\
\hline$p$ value & 0.014 & 0.081 & & 0.847 & 0.988 & $<0.001$ \\
\hline \multicolumn{7}{|c|}{$\operatorname{miR}-200 \mathrm{c}$} \\
\hline$r_{\mathrm{s}}$ & 0.005 & 0.514 & -0.040 & - & $0.855^{\mathrm{a}}$ & 0.221 \\
\hline$p$ value & 0.980 & 0.007 & 0.847 & & $<0.001$ & 0.299 \\
\hline \multicolumn{7}{|c|}{ miR-342-5p } \\
\hline$r_{\mathrm{s}}$ & 0.028 & $0.650^{a}$ & -0.003 & $0.855^{\mathrm{a}}$ & - & 0.277 \\
\hline$p$ value & 0.893 & 0.001 & 0.988 & $<0.001$ & & 0.191 \\
\hline \multicolumn{7}{|l|}{ Let-7a } \\
\hline$r_{\mathrm{s}}$ & $0.682^{a}$ & $0.650^{a}$ & $0.717^{\mathrm{a}}$ & 0.221 & 0.277 & - \\
\hline$p$ value & $<0.001$ & 0.001 & $<0.001$ & 0.299 & 0.191 & \\
\hline
\end{tabular}

$r_{\mathrm{s}}$, Spearman rank correlation coefficient.

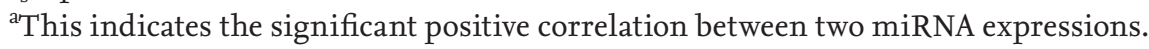

Table 3. Common target genes for positively correlated microRNAs

\begin{tabular}{|c|c|c|c|}
\hline Target gene & Pos & y correlated mi & NAs \\
\hline Eukaryotic translation initiation factor $2 \mathrm{C}, 4$ & miR-155-5p & $\operatorname{miR}-342-5 \mathrm{p}$ & hsa-let-7a-5p \\
\hline Insulin-like growth factor 2 (somatomedin A) & $\operatorname{miR}-155-5 \mathrm{p}$ & $\operatorname{miR}-342-5 p$ & hsa-let-7a-5p \\
\hline V-Ki-ras2 Kirsten rat sarcoma viral oncogene homolog & $\operatorname{miR}-155-5 \mathrm{p}$ & hsa-let-7a-5p & \\
\hline E2F transcription factor 2 & $\operatorname{miR}-155-5 \mathrm{p}$ & hsa-let-7a-5p & \\
\hline Phosphatase domain containing, paladin 1 & $\operatorname{miR}-155-5 \mathrm{p}$ & hsa-let-7a-5p & \\
\hline Growth differentiation factor 6 & $\operatorname{miR}-155-5 \mathrm{p}$ & hsa-let-7a-5p & \\
\hline Cytochrome b-561 domain containing 1 & $\operatorname{miR}-155-5 \mathrm{p}$ & hsa-let-7a-5p & \\
\hline WW domain binding protein 1-like & miR-155-5p & $\operatorname{miR}-342-5 p$ & \\
\hline Zinc finger protein $6_{52}$ & $\operatorname{miR}-155-5 \mathrm{p}$ & $\operatorname{miR}-342-5 p$ & \\
\hline GATS, stromal antigen 3 opposite strand & $\operatorname{miR}-155-5 p$ & $\operatorname{miR}-342-5 p$ & \\
\hline OTU domain, ubiquitin aldehyde binding 2 & $\operatorname{miR}-155-5 \mathrm{p}$ & $\operatorname{miR}-342-5 p$ & \\
\hline Caspase 3, apoptosis-related cysteine peptidase & $\operatorname{miR}-182-3 p$ & hsa-let-7a-5p & \\
\hline Ras association (RalGDS/AF-6) domain family member 2 & $\operatorname{miR}-200 c-3 p$ & $\operatorname{miR}-342-5 p$ & \\
\hline Vac14 homolog (Saccharomyces cerevisiae) & $\operatorname{miR}-200 c-3 p$ & $\operatorname{miR}-342-5 p$ & \\
\hline Immunoglobulin superfamily, member 10 & $\operatorname{miR}-200 c-3 p$ & $\operatorname{miR}-342-5 p$ & \\
\hline Sodium channel, voltage gated, type VIII, alpha subunit & $\operatorname{miR}-200 c-3 p$ & $\operatorname{miR}-342-5 p$ & \\
\hline
\end{tabular}

Adapted from National Chiao Tung University [13]. 
breast, and ovarian cancer cells inversely correlates with ZEB1 expression [18]. Cyclin-dependent kinase (CDK) 2 is a potential target of miR-20oc, which directly suppresses CDK2 expression in renal clear cell carcinoma cell lines and xenografts [16]. Cell cycle control genes, such as CDK2, CDK6, and cyclin A1, are reportedly ab- errantly overexpressed in patients with MDS [19,20]. Thus, the underexpression of miR-20oc may lead to cell growth and cell cycle progression in MDS by increasing levels of CDK2. Regarding miR-342-5p levels in patients with MDS, there have been controversial results. MiR342 is reported to be overexpressed in MDS with $\operatorname{del}(5 \mathrm{q})$

Table 4. Prognostic implications of clinical variables at the time of diagnosis and microRNAs

\begin{tabular}{|c|c|c|c|c|}
\hline Variable & OS at $2 \mathrm{yr}, \%$ & $p$ value & LFS at 2 yr, \% & $p$ value \\
\hline Age, yr & & 0.013 & & 0.016 \\
\hline$<65$ & 60.7 & & 61.8 & \\
\hline$\geq 65$ & 15.6 & & 16.0 & \\
\hline Sex & & 0.354 & & 0.405 \\
\hline Male & $34 \cdot 4$ & & $35 \cdot 4$ & \\
\hline Female & 56.3 & & 57.1 & \\
\hline Bone marrow blast, \% & & 0.010 & & 0.008 \\
\hline$<5$ & 68.8 & & 68.8 & \\
\hline$\geq 5$ & 21.6 & & 22.0 & \\
\hline IPSS & & 0.289 & & 0.222 \\
\hline Low & 100 & & 100 & \\
\hline Intermediate-1 & 52.9 & & 52.9 & \\
\hline Intermediate-2 & 22.2 & & 25.0 & \\
\hline High & 30.0 & & 30.0 & \\
\hline IPSS & & & & 0.051 \\
\hline Lower risk & & & 57.1 & \\
\hline Higher risk & & & 28.3 & \\
\hline R-IPSS & & 0.066 & & 0.054 \\
\hline Very low/low & 100 & & 100 & \\
\hline Intermediate & 50.8 & & 51.9 & \\
\hline High & $37 \cdot 5$ & & $37 \cdot 5$ & \\
\hline Very high & 18.8 & & 18.8 & \\
\hline \multicolumn{5}{|l|}{ miRNA expression } \\
\hline miR-124a (75\% quartile) & & 0.084 & & 0.054 \\
\hline Lower & 54.1 & & $54 \cdot 6$ & \\
\hline Higher & 16.7 & & 16.7 & \\
\hline miR-126 (median) & & 0.039 & & 0.038 \\
\hline Lower & 68.2 & & 68.2 & \\
\hline Higher & 24.2 & & 25.0 & \\
\hline miR-155 (75\% quartile) & & 0.003 & & 0.002 \\
\hline Lower & 60.8 & & 61.1 & \\
\hline Higher & 0 & & 0 & \\
\hline miR-708 (75\% quartile) & & 0.225 & & 0.144 \\
\hline Lower & 51.4 & & 51.9 & \\
\hline Higher & 20.0 & & 20.0 & \\
\hline
\end{tabular}

OS, overall survival; LFS, leukemia-free survival; IPSS, international prognostic scoring system; R-IPSS, revised IPSS. 

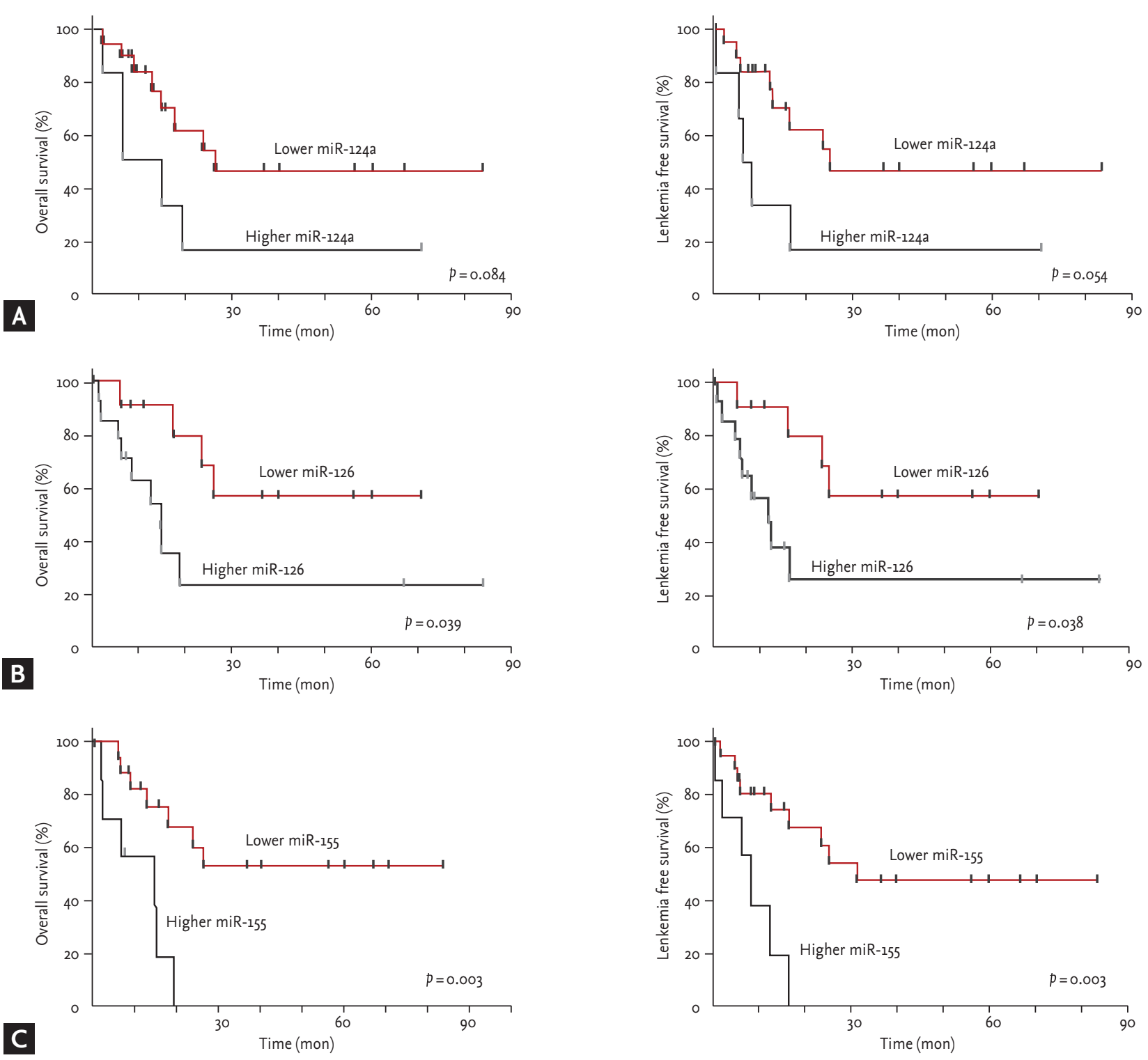

Figure 3. Association of expression levels of microRNA and survivals. (A) miR-124a, (B) miR-126, (C) miR-155.

[21], while it was underexpressed in another study [22]. Down-regulation of miR-124 in patients with MDS has been demonstrated in a previous study [23], and there was an inverse correlation between miR-124 expression and the degree of promoter methylation [24]. The une derexpression of Let-7a in patients with MDS has also been noted in previous studies [11,23]. Let-7a has been negatively correlated with RAS, and down-regulation of Let-7 family miRNAs might lead to overexpression of RAS [11].

We identified that the expression of miR-21, miR146b-5p, miR-126 and miR-155 were significantly high- er in higher risk (intermediate-2/high) than in lower risk (low and intermediate-1) according to the IPSS risk groups (lower vs. higher risk) (Fig. 2), and the results suggest that the miRNAs might be associated with MDS progression and leukemic transformation. miR-21 mediates hematopoietic suppression in MDS by activating transforming growth factor $\beta$ signaling [25].

The apoptotic features of early stage MDS are known to be lost during disease progression to late stage MDS [26]. MiR-146b-5p targets platelet-derived growth factor receptor $\alpha$, which negatively regulates erythropoiesis and megakaryocytopoiesis [27], and TRAF6 in dendrit- 
ic cell apoptosis [28]. An in vitro study using $\mathrm{K}_{5} 62$ cells demonstrated that miR-146b-5p within BCR-ABL1-positive microvesicles promoted leukemic transformation of hematopoietic cells [29]. MiR-146b expression tended to increase according to increment of bone marrow fibrosis grade in patients with myeloproliferative neoplasms [30]. These results suggest that miR-146b-5p inhibits the apoptotic pathway and may have an important role in MDS progression.

We identified that higher expression levels of miR126 and miR-155 could not only distinguish higher from lower risk MDS but also significantly correlated with shorter OS and transformation risk to AML in MDS patients. As consistent to our result, Sokol et al. [23] also showed that overexpression of miR-126 in higher risk MDS comparing to lower risk MDS using miRNA array. MiR-126 is known to be associated with angiogenesis and megakaryocytopoiesis [31,32], as it regulates HOXA9 by binding to the homeobox [33]. The cluster of HOX genes has been implicated in early hematopoiesis as well as leukemogenesis [33]. MiR-126 is upregulated by epigenetic therapy with azacitidine or histone deacetylase inhibitor 4-phenylbutyric acid [32].

Our data revealed that miR-155 expressions both in lower and higher risk MDS were lower in normal controls. But, the depth of miR-155 underexpression in MDS did not correlate with the depth of disease. Among MDS patients, the relatively higher expressions of miR155 had an adverse prognostic significance. Higher miRNA-155 levels in higher risk MDS compared to lower-risk MDS have also been demonstrated in a previous study [23]. Moreover, miR-155 expression in AML has been also reported to be overexpressed [34]. MiR-155 is a translational repressor of several myeloid transcription factors including PU.1, C/ERB $\beta$, and CSF1R [35,36], and mice transplanted with miR-155-transfected stem cells developed a myeloproliferative disorder with abnormal granulocyte morphology analogous to MDS [35]. The dysregulation of miR-155 within the primitive bone marrow compartment may promote aberrant hematopoietic stem cell self-renewal and progression to AML [5]. MiR-155 targets SHIP-1 gene which was expressed in MDS progenitor cells. Loss of SHIP-1 protein expression may result in myeloid leukemia growth [26]. These findings suggest a role of miR-155 in MDS progression. Thus, we suspect that underexpression of miR-155 may be associated with the development of early stage MDS. And the reincrease of underexpressed miR-155 levels may be a possible mechanism of MDS progression and the leukemic transformation. There may be some genetic alterations other than miR-155 having more important role in the pathogenesis of advanced MDS.

As shown in Fig. 1, miR-124a underexpression may be a role in pathogenesis of MDS. In addition, miR-124a tended to be associated with OS and LFS, although there were no differences in miR-124a levels between higher and lower risk MDS patients. MiR-124a expression inversely correlates with promoter methylation [24]. Thus, relatively higher miR-124a expressions in MDS patients might lead to poor response to hypomethylating agents and this might have an adverse impact on progression to AML and survivals. Further investigations are needed to define the mechanism of miR-124a and miR-155 in MDS pathogenesis and prognosis. Although our study was limited by the relatively small number of patients included, we identified several miRNAs associated with pathogenesis, leukemic transformation, and prognosis in MDS.

\section{KEY MESSAGE}

1. MiR-124a, miR-155, miR-182, miR-20oc, miR342-5p, and Let-7a expressions might be associated with myelodysplastic syndrome (MDS) pathogenesis.

2. MiR-21, miR-126, 146b-5p, and miR-155 might be associated with MDS progression.

3. The higher expressions of miR-126 and miR-155 may predict significantly worse prognosis.

\section{Conflict of interest}

No potential conflict of interest relevant to this article was reported.

\section{Acknowledgments}

The biospecimen and data used in this study were provided by Asan Bio-Resource Center, Korea Biobank Network (2010-0093). This study was supported by a grant from the Korean Health Technology R\&D Project, Ministry of Health and Welfare, Republic of Korea (HI12Co129). 


\section{REFERENCES}

1. List AF, Vardiman J, Issa JP, DeWitte TM. Myelodysplastic syndromes. Hematology Am Soc Hematol Educ Program 2004:297-317.

2. Park EH, Lee H, Won YJ, et al. Nationwide statistical analysis of myeloid malignancies in Korea: incidence and survival rate from 1999 to 2012. Blood Res 2015;50:204-217.

3. Greenberg P, Cox C, LeBeau MM, et al. International scoring system for evaluating prognosis in myelodysplastic syndromes. Blood 1997;89:2079-2088.

4. Greenberg PL, Tuechler H, Schanz J, et al. Revised international prognostic scoring system for myelodysplastic syndromes. Blood 2012;120:2454-2465.

5. Rhyasen GW, Starczynowski DT. Deregulation of microRNAs in myelodysplastic syndrome. Leukemia 2012;26:1322.

6. Bartel DP. MicroRNAs: genomics, biogenesis, mechanism, and function. Cell 2004;116:281-297.

7. Khraiwesh B, Arif MA, Seumel GI, et al. Transcriptional control of gene expression by microRNAs. Cell 2010;140:111-122.

8. O'Connell RM, Zhao JL, Rao DS. MicroRNA function in myeloid biology. Blood 2011;118:2960-2969.

9. Choi JS, Nam MH, Yoon SY, Kang SH. MicroRNA-194-5p could serve as a diagnostic and prognostic biomarker in myelodysplastic syndromes. Leuk Res 2015;39:763-768.

10. Kim Y, Cheong JW, Kim YK, et al. Serum microRNA-21 as a potential biomarker for response to hypomethylating agents in myelodysplastic syndromes. PLoS One 2014;9:e86933.

11. Vasilatou D, Papageorgiou SG, Kontsioti F, et al. Expression analysis of mir-17-5p, mir-20a and let-7a microRNAs and their target proteins in $\mathrm{CD}_{34}+$ bone marrow cells of patients with myelodysplastic syndromes. Leuk Res 2013;37:251-258.

12. Vardiman JW, Thiele J, Arber DA, et al. The 2008 revision of the World Health Organization (WHO) classification of myeloid neoplasms and acute leukemia: rationale and important changes. Blood 2009;114:937-951.

13. National Chiao Tung University. miRTarBase [Internet]. Hsinchu (TW): National Chiao Tung University, c2017 [cited 2016 Apr 20]. Available from: http://mirtarbase.mbc. nctu.edu.tw.

14. Shelygin YA, Shubin VP, Frolov SA, et al. The analysis of microRNAs miR-20oC and miR-145 expression in col- orectal cancer of different molecular subtypes. Dokl Biochem Biophys 2015;463:243-246.

15. Ibrahim FF, Jamal R, Syafruddin SE, et al. MicroRNA-200c and microRNA-31 regulate proliferation, colony formation, migration and invasion in serous ovarian cancer. $\mathrm{J}$ Ovarian Res 2015;8:56.

16. Wang X, Chen X, Han W, et al. miR-2ooc targets CDK2 and suppresses tumorigenesis in renal cell carcinoma. Mol Cancer Res 2015;13:1567-1577.

17. Wang J, Zhao H, Tang D, Wu J, Yao G, Zhang Q. Overexpressions of microRNA- 9 and microRNA-200c in human breast cancers are associated with lymph node metastasis. Cancer Biother Radiopharm 2013;28:283-288.

18. Cochrane DR, Spoelstra NS, Howe EN, Nordeen SK, Richer JK. MicroRNA-200c mitigates invasiveness and restores sensitivity to microtubule-targeting chemotherapeutic agents. Mol Cancer Ther 2009;8:1055-1066.

19. Shi J, Shao ZH, Liu H, et al. Expression of cell cycle control genes in myelodysplastic syndromes. Zhonghua Xue Ye Xue Za Zhi 2005;26:10-14.

20. Jia JS, Xu SR. Expression of cyclin A1 mRNA in patients with myelodysplastic syndrome and its clinical significance. Zhongguo Shi Yan Xue Ye Xue Za Zhi 2009;17:377381.

21. Hussein K, Theophile K, Busche G, et al. Aberrant microRNA expression pattern in myelodysplastic bone marrow cells. Leuk Res 2010;34:1169-1174.

22. Votavova H, Grmanova M, Dostalova Merkerova M, et al. Differential expression of microRNAs in CD34+ cells of 5q- syndrome. J Hematol Oncol 2011;4:1.

23. Sokol L, Caceres G, Volinia S, et al. Identification of a risk dependent microRNA expression signature in myelodysplastic syndromes. Br J Haematol 2011;153:24-32.

24. Dickstein J, Senyuk V, Premanand K, et al. Methylation and silencing of miRNA-124 by EVIr and self-renewal exhaustion of hematopoietic stem cells in murine myelodysplastic syndrome. Proc Natl Acad Sci U S A 2010;107:9783-9788.

25. Bhagat TD, Zhou L, Sokol L, et al. miR-21 mediates hematopoietic suppression in MDS by activating TGF- $\beta$ signaling. Blood 2013;121:2875-2881.

26. Lee DW, Futami M, Carroll M, et al. Loss of SHIP-1 protein expression in high-risk myelodysplastic syndromes is associated with miR-210 and miR-155. Oncogene 2012;31:4085-4094.

27. Zhai PF, Wang F, Su R, et al. The regulatory roles of mi- 
croRNA-146b-5p and its target platelet-derived growth factor receptor $\alpha$ (PDGFRA) in erythropoiesis and megakaryocytopoiesis. J Biol Chem 2014;289:22600-22613.

28. Park H, Huang X, Lu C, Cairo MS, Zhou X. MicroRNA-146a and microRNA-146b regulate human dendritic cell apoptosis and cytokine production by targeting TRAF6 and IRAK1 proteins. J Biol Chem 2015;290:28312841.

29. Zhang HM, Li Q, Zhu X, et al. miR-146b-5p within BCR-ABL1-positive microvesicles promotes leukemic transformation of hematopoietic cells. Cancer Res 2016;76:2901-2911.

30. Ha JS, Jung HR. Up-regulation of MicroRNA 146b is associated with myelofibrosis in myeloproliferative neoplasms. Ann Clin Lab Sci 2015;45:308-314.

31. Garzon R, Pichiorri F, Palumbo T, et al. MicroRNA fingerprints during human megakaryocytopoiesis. Proc Natl Acad Sci U S A 2006;103:5078-5083.

32. Saito Y, Friedman JM, Chihara Y, Egger G, Chuang JC,
Liang G. Epigenetic therapy upregulates the tumor suppressor microRNA-126 and its host gene EGFL7 in human cancer cells. Biochem Biophys Res Commun 2009;379:726-731.

33. Shen WF, Hu YL, Uttarwar L, Passegue E, Largman C. MicroRNA-126 regulates HOXA9 by binding to the homeobox. Mol Cell Biol 2008;28:4609-4619.

34. Garzon R, Volinia S, Liu CG, et al. MicroRNA signatures associated with cytogenetics and prognosis in acute myeloid leukemia. Blood 2008;111:3183-3189.

35. O'Connell RM, Rao DS, Chaudhuri AA, et al. Sustained expression of microRNA-155 in hematopoietic stem cells causes a myeloproliferative disorder. J Exp Med 2008;205:585-594.

36. Georgantas RW 3rd, Hildreth R, Morisot S, et al. CD $34+$ hematopoietic stem-progenitor cell microRNA expression and function: a circuit diagram of differentiation control. Proc Natl Acad Sci U S A 2007;104:2750-2755. 